\title{
Transvers Vajinal Septumu Olan Adölesana Yönelik Psikososyal Sorunlara İlişkin Hemşirelik Bakımı
}

\author{
Sultan Özkan Şat $\odot$, Canan Uçakcı Asalıoğlu@ $\odot$, Şengül Yaman Sözbir $\odot$
}

Gazi Üniversitesi Sağlık Bilimleri Fakültesi, Hemşirelik, Ankara, Türkiye

Sultan Özkan Şat, Arş. Gör. Canan Uçakcı Asalıŏlu, Arş. Gör. Şengül Yaman Sözbir, Doç. Dr.
İletişim:

Arş. Gör. Sultan Özkan Şat Gazi Üniversitesi Sağlık Bilimleri Fakültesi, Hemşirelik, Ankara, Türkiye Tel: +903122162896

E-Posta: sultan.0zkan25@gmail.com
Gönderilme Tarihi : 15 Haziran2017

Revizyon Tarihi ： 21 Eylül 2017

Kabul Tarihi : 30 Eylül 2017

\section{ÖZET}

Embriyonik dönemde genital organların oluşması esnasında konjenital defektler oluşabilmektedir. Bu defektlerden biri vajinal septumdur. Bu olgu sunumunda 13 yaşındaki transvers vajinal septum tanılı adölesan hastanın yaşadığı psikososyal sorunlar ele alınmıştır. Bu sorunlara yönelik durumsal düşük benlik saygısı, etkisiz bireysel baş etme, sosyal etkileşimde bozulma, anksiyete ve post travma sendromu riski tanıları ve hemşirelik girişimleri tartışılmıştır.

Anahtar sözcükler: Vajina, agenez, adölesan, psikososyal sorun, hemşirelik bakımı

\section{NURSING CARE OF RELATED TO PSYCHOSOCIAL PROBLEMS IN ADOLESCENTS WITH TRANSVERSE VAGINAL SEPTUM}

\section{ABSTRACT}

Congenital defects may occur during the formation of genital organs in the embryonic period. One of these defects is the vaginal septum. Psychosocial problems of a 13 -year-old adolescent patient with transverse vaginal septum were discussed in this case report. Nursing diagnoses such as situational low self -esteem, ineffective individual coping, impaired social interaction, anxiety and risk for post-trauma syndrome as well as nursing interventions for these problems were discussed.

Keywords: Vagina, agenesis, adolescent, psychosocial problem, nursing care, vaginal septum, septum

mbriyonik dönemde müller kanallarının birleşerek genital organları meydana getirmesi esnasında kanalın alt kısmında oluşan konjenital defektlerden biri de vajinal septumdur $(1,2)$. Embriyonik dönemde maruz kalınan teratojenik ajanlar, enfeksiyonlar, anoksi veya genetik faktörler vajinal septumun da içinde bulunduğu genital organ anomalilerine yol açabilmektedir (1). Vajinal septum transvers ve longitidunal olmak üzere iki şekilde görülebilmektedir $(1,2)$. Longitidunal vajinal septum vakaları genellikle ilk cinsel ilişkiye kadar, hatta bazı vakalarda vajinal doğuma kadar herhangi bir belirti vermezken, transver vajinal septum vakaları puberteye girişle birlikte primer amenore, pelvik ağrı ve distansiyon şikayeti ile ortaya çıkmaktadır (3). Müllerian gelişim bozukluğu olgularında, tedavinin primer amacı, hastaların normal bir cinsel hayata sahip olabilmeleri için cerrahi olarak yeniden bir vajen oluşturulmasıdır. Yeni bir vajen oluşturulması neovajinoplasti teknikleri olarak adlandırılmakta ve seri dilatasyon uygulamalarının yanı sıra, Mc Indoe, intestinal vajinoplasti gibi birçok farklı operatif girişimsel tekniği içermektedir (4). 
Müllerian kanal anomalileri başlıca menstrual ve cinsel sorunlara yol açmakta; bu sorunlar cerrahi ile tedavi edilmektedir. Ancak tanı aşaması, tedavi ve bundan sonraki yaşama uyum açısından birçok fiziksel, psikolojik ve sosyal sorunlar yaşanabilmektedir. Bu nedenle hastalara multidisipliner bir yaklaşım gerekmektedir. Türkiye'de ve dünyada yapılan çalışmalar bu olgularda depresyon, damgalanma, sosyal etkileşimde bozulma, ümitsizlik, beden algısında bozulma, cinsel kimliğin oluşumuna yönelik sorunlar ve özgüven eksikliğinin sık karşılaşılan psikososyal problemler arasında yer aldığını göstermektedir (5-7). Bu olgular kompleks olup nadir görülmektedir. Bu nedenle hastalarla en çok iletişim halinde olan hemşirelerin bu tür vakaları psikososyal açıdan ele alması ve yaşanılan durumun atlatılmasında ihtiyaç duyulan danışmanlık ve bakımı sağlamaları önem arz etmektedir.

Bu makalede tartışacağımız vaka adölesan dönem özellikleri göstermektedir. Adölesan dönem, kişinin kendi kendini kabul etmeye başladığı, benlik algısını oluşturduğu, cinsel ilginin genital bölgeye yoğunlaştığı ve cinsel kimliğin cinsiyet ile özdeşleştirildiği bir kriz dönemidir (8). İlginin cinsel organ ve cinselliğe kaydığı bu dönemde transvers vajinal septum gibi cinsel organlara yönelik konjenital defektler adölesanda cinsel kimlik gelişimi ve benlik saygısını olumsuz etkileyebilmektedir. Adolesan dönemde kimlik oluşumu gerçekleştiği için bireyler belirsizlik ve tutarsız davranışlar sergilemektedir. Bu nedenle hemşireler bu dönemin özel gereksinimlerine uygun bakım vermelidir. Bu çalışmada adolesan dönemde transvers vajinal septum nedeniyle opere edilen bir hastanın psikososyal sorunlarına yönelik hemşirelik bakımı ele alınmıştır.

\section{Olgu}

1. Geçmiş sağlık öyküsü

Şu an 13 yaşında olan hasta 7 aylıkken yarık damak ve çene cerrahisi, 6 yıl önce ise atrial septal defekt nedeniyle operasyon geçirmiştir. Hastanın geçirdiği operasyonlara yönelik tıbbi takipleri devam etmektedir. Konjenital defektleri göz önünde bulundurularak hastanın annesine gebelikte maruz kalınabilecek teratojenler sıralanmış, anne gebelik boyunca bu teratojenlerden herhangi birine maruz kalmadığını ifade etmiş ve akraba evliliği olmadığını belirtmiş̧ir. Ayrıca hastanın anne ve babası herhangi bir kronik hastalığının olmadığını ifade etmiştir. Hastaya 2 yıl önce puberte prekoks tanısı ile $3.75 \mathrm{mg}$ leuprolide asetat tedavisi uygulanmıştır. Hasta 6 aydır ilacın kesilmesine rağmen menarş olmamıştır. Geçmiş sağlık öyküsünde başka bir özellik bulunmamaktadır.

\section{2. Şimdiki sağlık öyküsü ve alınan tedavi ve bakım}

\section{uygulamaları}

Hasta şiddetli pelvik ağrı şikayetiyle acil servise başvurmuş ve transvers vajinal septum tanısı ile acil ameliyata alınmıştır. Hastaya transvers septum rezeksiyonu yapılmış ve hemeotokolpos boşaltılmıştır. Hastaya ameliyatta 6 ay süreli obturator takılmıştır. Hastada ameliyat sırasında taşikardi gelişmiş olup zorlu entübasyon öyküsü mevcuttur. Post-op dönemde solunum sıkıntısı ve kusma yaşamıştır. Bu şikayetler nedeniyle kardiyoloji ve göğüs hastalıklarına konsültasyon istenmiş ve konsültasyon sonucunda önemli bir sorun saptanmamıştır. Ameliyattan sonra 7. Günde takip edilen hasta R2 diyet almakta ve yaşamsal bulguları stabil seyretmektedir. Obturator bakımı antiseptikli solüsyon ile günde bir kere (Defekasyona çıtığı zaman) anne tarafından yapılmaktadır.

Hasta ameliyat sonrasında proflaksi amaçlı iesef (1 $\mathrm{g}$ IV $\left.2^{*} 1\right)$, Metronidazol (10 ml infüzyon $\left.3^{*} 1\right)$, ağrıyı gidermek için Parol (infüzyon $3^{*} 1$ ), sıvı elektrolit dengesini sürdürmek için ise Laktatlı ringer ( $1 * 1)$ tedavisi almıştır.

\section{Hasta ve ailesinin psikososyal öyküsü}

Hasta ailenin ilk ve tek çocuğudur. Hasta anomalili doğduğu için ailesi başka bir gebelik planlamamıştır. Hastanın geçirdiği operasyon hala dayı gibi birkaç yakın akrabası dışında kimseye söylenmemiştir. Aile bunlar dışındaki akrabalara ise amenore tanısı ile hastanede yattığını ifade etmiştir. Hastanın babası ameliyatı kabullenememiş ve öfkeli tavırlar sergilemiştir. Bu durumu "Bu daha çocuk, nasıl başına gelir? Bu durumla nasıl baş edecek? Bu aleti nasıl takacak? O bunu kaldıramaz. Daha çok küçük." gibi cümlelerle ifade etmiştir. Annesi obturator takılmasını ve bakımını üstlenmiş ve bu durumu" Bunu hep ben yapmak zorundayım, çocuğum yapamaz. Bunu yaparken canı yanacak diye çok korkuyorum, bu çocuğumu kısıtlıyor. Evde de bunu ben yapmak zorundayım" ifadeleri ile belirtmiştir.

Ailesi küçüklüğünden itibaren perine bölgesinin korunması, anne ve baba dışında kimsenin dokunmaması ve görmemesi gereken bir bölge olduğu konusunda kesin bir şekilde hastaya bilgi verdiğini ifade etmiştir. Tanı aşamasında hastanın mahremiyetine saygı duyulmaksızın sağlık personeli perine bölgesini kalabalık ortamda açarak herkesin görmesine neden olmuş ve hasta bu durumdan çok etkilendiğini belirtmiş̧ir. Operasyon sonrası hasta vajene yönelik tüm uygulamalarda (ör obturator takımı) ajite tavırlar sergilemiş, sadece annesinin görmesine ve dokunmasına izin vermiştir. Hasta obturator kullandığını babasından gizlenmesini istemiştir. 
Hastanın obturator nedeniyle yaşadığı hareket kısıtlılığı kendini bağımlı hissetmesine ve öfkeli davranışlar sergilemesine neden olmuştur.

Hastayla hastalığı ve evde bakımına ilişkin konuşulmak istendiğinde hasta konuşmaktan kaçınmış ve uyuyormuş görüntüsü sergilemiştir. Sonraki günlerde konuşulduğunda hasta kendisini çirkin gördüğünü ve yaratık gibi hissettiğini ifade etmiştir. Hastanın öz bakımını ihmal ettiği, aynaya bakmak ve kendini görmek istemediği gözlenmiştir. Hasta koridorda mobilize olmayı reddetmiş, diğer hastalarla iletişim kurmaktan uzak durmuştur. Hasta arkadaşlarının hastalığını, geçirdiği operasyonu bilmesini ve kendisini hastanede o halde görmelerini istemediğini belirtmiş ve bu nedenle ziyaretçi kabul etmemiştir.

Hastadan hastanede kalma ve hastalığı ile ilgili duygularını çizerek anlatması istenilmiş ve hasta tarafından resim çizilmiştir. Hasta yaptığı resimde (Şekil 1) yeşil ile belirtilmiş alandaki kişinin kendisi olduğunu kanepede oturan ve gülümseyen kişinin ise annesi olduğunu ifade etmiştir. Odasına hemşirelerin sürekli girdiklerini ve kapının önündeki kişinin hemşire olduğunu belirtmiştir. Hastaya kolundaki ve perine bölgesindeki çizimlerin ne olduğu sorulduğunda kolundaki çizdiği noktanın ilaç verilen alet olduğunu, perine bölgesindekinin ise ameliyatta takılan alet olduğunu belirtmiştir. Merdiven şeklindeki yeşil çizimin evine giden yol olduğunu belirtmiştir. Ayrıca ameliyat öncesinde diğer hasta odalarına gittiğini belirtmiş ve onları da resimde üzgün surat şeklinde çizdiğini belirtmiştir.
Kendi yüz ifadesini ise ifadesiz olarak çizmiştir. Gün boyunca kendisi ile birlikte olan babasını resme çizmemiştir. Hastanın yaptığı resim Çocuk Sağığı ve Hastalıkları Hemşireliği alanında bir uzman tarafından değerlendirilmiş ve hastanın yaptığı resimde yoğun bir kaygı duygusunun olduğu, kendine güvensizlik ve yetersizlik duygusu yaşadığı belirtilmiştir. Genital bölgeyi karalı olarak çizmesi ve obturatoru genital bölgede ancak vücut dışında görünür şekilde ve büyük olarak çizmiş olmasından bu kaygının yoğun olarak genital bölgesinde takılı olan obturatora yönelik olduğu yorumlanmıştır. Resimde çocuğun utangaçlık ve çekingenliğinin olduğu görülmüştür.

\section{Hastanın psikosyal sorunlarına yönelik hemşirelik uygulamaları}

Hastanın psikososyal verileri toplanmış ve saptanan sorunlar hemşirelik bakım süreci ile ele alınmıştır.

Beden imgesinde rahatsızlık: Adölesan dönemde vücut değişiklikleri ve cinsellik adölesanlar için en önemli konuları oluşturmaktadır (9). Hastanın kendisini çirkin gördüğünü ve yaratık gibi hissettiğini ifade etmesi, aynaya bakmak ve kendini görmek istememesi, çizdiği resimde perine bölgesini kapatmış olması (Şekil 1) ve cinselliğe yönelik ilgilerinin arttığı bu dönemde cinsel bölgesine yönelik bir operasyon geçirmiş olması beden imgesinde rahatsızlık tanısını koymamıza neden olmuştur. Beden imgesinde rahatsızlık tanısına yönelik geçirilen operasyonun hasta ve ailesi için anlamı ve duygusal anlamda değeri tartışılmış;

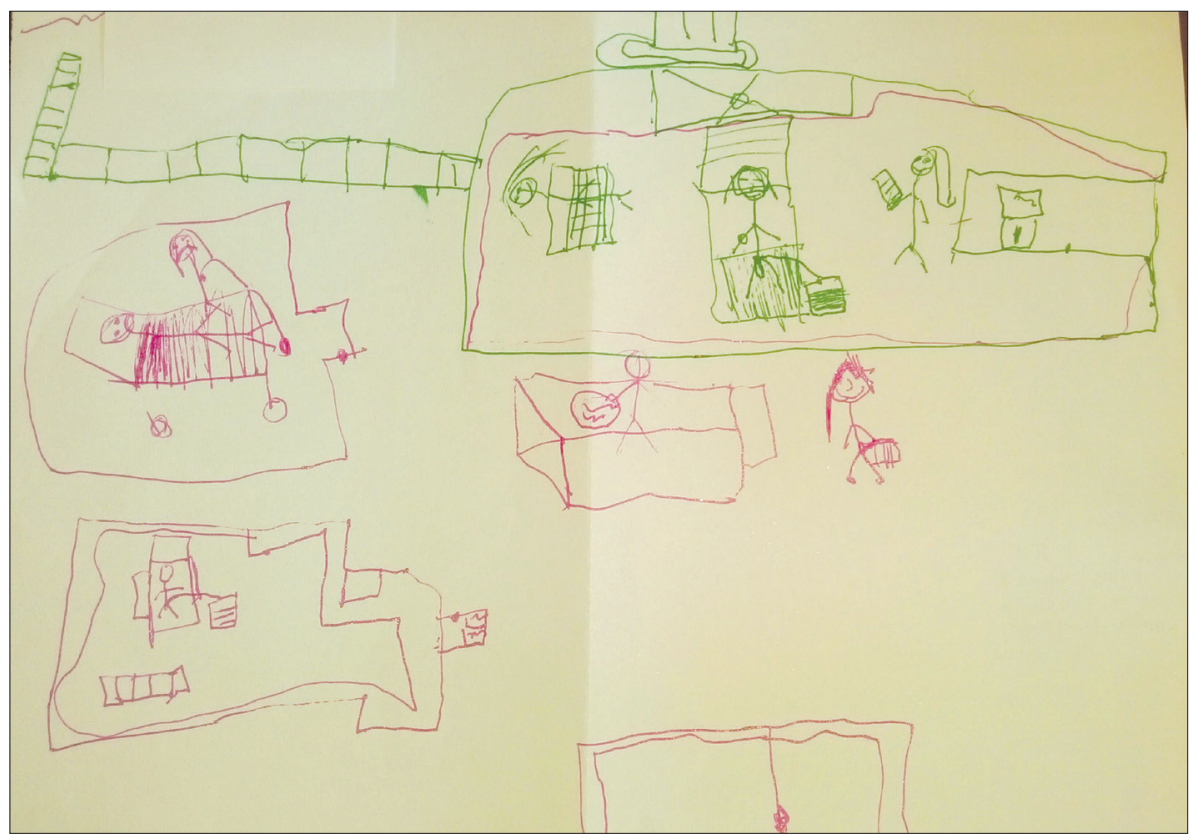

Şekil 1. Hastaya veri toplama aşamasında çizdirilen resim. 
buna yönelik duygu, düşünce ve bakış açısı ifade ettirilmiştir. Operasyon ve evde bakıma ilişkin merak ettiği sorular cevaplandırılmış ve yanlış anlamaları düzeltilmiştir. Hastanın perine bölgesine ve obturatora aşamalı olarak bakması ve dokunması sağlanmıştır. Girişimler sonucunda hasta operasyona ilişkin daha rahat konuşmaya başlamış, obturatoru kendisi takmayı öğrenmeyi istemiştir.

Durumsal düşük benlik saygısı: Durumsal düşük benlik saygısı, önceden olumlu bir benlik saygısına sahipken bir duruma tepki olarak kendisi hakkında negatif duygular yaşayan bireydeki durumdur (10). Hastanın öz bakımını ihmal etmesi, mobilize olmak istememesi, sürekli yatakta yarı uyur halde olması, diğer hastalarla iletişim kurmaktan uzak durması ve arkadaşlarının kendisini hastanede o halde görmelerini istemediğini belirtmesi durumsal düşük benlik saygısı tanısını koymamıza neden olmuştur. Buna yönelik; hastaya kendine ilişkin duygu ve düşünceleri ifade ettirilmiş; olumlu yetenekleri ve özellikleri konusunda düşünmesi istenmiştir. Hasta arkadaşları ile görüşmesi yönünde desteklenmiş, serviste akran olduğu hastalarla iletişime geçmesi sağlanmışır. Hastanın kendi eşyaları ve yaptığı resimlerle odası kişiselleştirilmiştir. Girişimler sonucunda hasta daha sık mobilize olmaya başlamış, servisteki diğer hastalarla iletişim kurmuş ve kuzeninin hastanede kendini ziyaretini kabul etmiştir.

Etkisiz bireysel baş etme: Stresörlere etkili şekilde uyum sağlamayan bireydeki durumu tanımlamaktadır (11). Hastanın iletişime kapalı olması, öfkeli davranışlar sergilemesi, öz bakımını ihmal etmesi, ziyaretçi istememesi ve hastalığı ile ilgili konuşmaktan kaçınması bizi bu tanıya götürmüştür. Buna yönelik öfkeli davranışlara neden olduğu gözlenen obturator takılması işlemi, sağılık personelinin sık sık ve izin istemeden odaya girip çıkması ve perine bakımı işlemleri sırasında hastanın sadece izin verdiği kişiler (annesi ve bir hemşire) ve izin verdiği ölçüde mahremiyetine ve otonomisine saygı duyularak girişimlerde bulunulmuştur. Hastayla hastalığı, operasyon süreci ve bundan sonraki yaşamına yansımaları hakkında konuşulmuş, kabullenmesi için desteklenmiştir. Girişimler sonucunda hastanın öfkeli davranışları ortadan kalkmış, daha fazla sağlık personelinin kendisine bakım vermesine izin vermiş, hastalığı ve bakımı hakkında daha rahat konuştuğu gözlenmiş ve öz bakımına daha fazla katılmaya başlamıştır.

Sosyal etkileşimde bozulma: Sosyal etkileşimde bozulma, etkileşimlerinden olumsuz, yetersiz ya da doyumsuz tepkiler alan/yaşayan ya da bu riski taşıyan bireydeki durumdur (10). Hastanın adölesan dönemde iken genital bölgeye yönelik operasyon geçirmesi bu riski ortaya çıkarmıştır. Hastanın konuşmaktan kaçınması, arkadaşları ve diğer akrabalarının ziyarette bulunmasını istememesi ve klinikteki diğer hastalarla iletişim kurmaması bu tanıyı koydurmuştur. Tanıya yönelik hasta ile güven verici iletişim kurulmaya çalışılmış, gizliliği ve mahremiyeti konusunda güvende hissetmesi sağlanmaya çalışılmış ve hasta aynı tanıya sahip olmasa bile hastanede yatan akranları ile iletişim kurması konusunda desteklenmiştir. Hasta girişimler sonrası klinikteki akranları ile daha sık iletişime geçmiş ve kuzeninin hastanede kendini ziyaret etmesine izin vermiştir.

Anksiyete: Anksiyete, belirsiz spesifik olmayan bir tehdide karşı otonom sinir sistemi aktive olan ve huzursuzluk yaşayan birey ya da grubun durumudur (10). Adölesan dönemde seksüel gelişim ve akran ilişkilerinde değişim gibi benlik kavramını tehdit eden durumlar karşısında anksiyete ortaya çıkmaktadır (11). Hastanede yatmak ve hasta olmak adölesanlar için kabullenilmesi güç bir durumdur. Adölesanlar bu nedenle genellikle durumu kabullenmeme, hastanede yatıyor olduğunu saklama, tedaviyi kabullenmeme ve öfke tepkileri ortaya koymaktadır (8). Hastanın verilerinde yer aldığı üzere çevresine karşı öfkeli davranışları bulunmaktaydı ve bu öfkenin özellikle obturator bakımı sırasında yaşandığı gözlenmiştir. Bununla birlikte hastanın çizdiği resmin analizinde obturatora yönelik yoğun kaygı ve kendine güvensizlik/yetersizlik yaşadığı belirlenmiştir. Hastanın gözlenen davranışları ve resim analizinden yola çıkılarak anksiyete tanısı konmuştur. Buna yönelik hastayla güven ilişkisi oluşturulduktan sonra obturator kullanımının hasta için anlamı üzerine konuşulmuştur. Hastamız obturatorun günlük yaşamında vajen çıkıp düşebileceği yönünde korku yaşadığını ifade etmiştir. Obturator kullanımı hakkında hasta bilgilendirilmiş ve bu korkusu giderilmiştir. Hastamız ayrıca annesinin kendisine yönelik ileride evlilik ve çocuk sahibi olmaya yönelik sorun yaşayabileceği duygularından kendisinin de etkilendiğini ve kaygılandığını belirtmiştir. Hastaya üreme organları, cinsel birleşme, gebeliğin oluşumu konularında eğitim verilmiştir. Daha sonra hastanın aşamalı olarak önce obturatora bakması, dokunması ve kullanması sağlanmıştır. Hastamız hastaneden ayrılmadan önce öfke tepkisi ortadan kalmış ve obturator kullanımını kendisi yapmaya başlamıştır.

Post travma sendromu riski: Post travma sendromu, dayanılamayan, içine sindirilemeyen bir ya da daha fazla travmatik olaya karşı devamlı acı bir tepki yaşama durumudur (10). Hastamız tanı aşamasında travmatize olmuş 
ve psikososyal hazırlığı tam olarak yapılmadan opere edilmiştir. Travmatik olay sonrasında; kişi yaşadığı olayları uykuda ve uyanıkken tekrar tekrar yaşayabilir, kişinin yaşadığı ruhsal sıkıntılar zamanla kronik bir duruma dönüşebilir. Olayın üzerinden ne kadar süre geçmiş olursa olsun, travmanın bu etkileri tekrar tekrar yaşanabilmektedir (12). Bu nedenle hastamızda post travma sendromu riski tanısı ele alınmıştır. Buna yönelik vakanın tanı aşamasında yaşadıklarına dair geriye dönüşler, tekrarlayan rüyalar ve kabuslar görüp görmediği sorgulanmıştır. Tanı aşamasıyla ilgili sık sık konuşup konuşmadığı gözlenmiştir. Bununla birlikte kendini suçlama, utanç, çaresizlik, anksiyete, öfke patlamaları ve tetikte olma açısından değerlendirilmiştir. Hastanın öfke patlamaları, anksiyete ve tetikte olma davranışları sergilediği ve yaptığı resimde utanç yaşadığı gözlemlenmiştir. Buna yönelik, hastanın psikolog tarafından değerlendirilmesi sağlanmıştır.

Adölesan dönemde üreme organlarına yönelik neredeyse bütün müdahaleler kişinin psikososyal sağlığını olumsuz etkileyebilmektedir. Hastamızda beden imgesinde rahatsızlık, durumsal düşük benlik saygısı, etkisiz bireysel baş etme, sosyal etkileşimde bozulma, anksiyete ve post travma sendromu riski ele alınmış ve bunlara yönelik hemşirelik girişimleri uygulanmıştır. Çalışmamızda hasta operasyon öncesi görülmemiş, operasyon sonrası 7. Günden itibaren 5 gün boyunca ele alınmıştır. Bu çalışmamız için önemli bir sınırlılıktır. Çalışmamız sonucunda transvers vajinal septum nedeniyle opere edilen adölesanların birçok psikososyal sorunlar yaşadıkları ortaya konmuş ve buna yönelik öneriler geliştirilmiştir. Transvers vajinal septum nedeniyle opere edilen adölesanların; operasyon öncesinden başlanarak psikososyal açıdan ele alınması, operasyon ve sonrasına hazırlanması, yapılan işlemlerde mahremiyetin korunması, otonomilerinin desteklenmesi, operasyon sonrası psikososyal açıdan ele alınması ve ailelerinin de psikososyal etkilenmelerini ortaya koyan çalışmaların yapılması önerilmektedir.

\section{Tartışma}

Vajinal agenezis, vajinal septum gibi genital organ anomalilerinde hastaların fiziksel sorunların yanı sıra sıklıkla psikososyal sorunlar yaşadıkları da bilinmektedir (13).
Vajenin anatomik olarak yapılmış olması sadece fiziksel işlev sorununu çözmekte ancak beraberinde psikososyal sorunlara neden olabilmektedir (14-16). Yapılan çalışmalarda bu olgularda depresyon, cinsel sorunlar, anksiyete, toplumsal cinsiyet kimliği algısında ve benlik saygısında bozulma gibi psikososyal sorunlar olduğu bildirilmektedir $(6,7,16,17)$. Türkiye'de vajinal agenezisde yaşanan psikososyal sorunlara ilişkin yazılmış sadece bir çalışmaya ulaşılabilmiştir (5). Yaman ve Ayaz (2014) çalışmalarında yaşanan psikososyal sorunlar arasında suçluluk, ümitsizlik ve depresyon olduğunu belirtmiş̧lerdir. Bu olguda psikosoyal sorunlara yönelik durumsal düşük benlik saygısı, etkisiz bireysel baş etme, sosyal etkileşimde bozulma, anksiyete ve post travma sendromu riski sorunları olduğu saptanmış ve buna yönelik hemşirelik girişimleri uygulanmıştır. Çalışma bulgularımız literatürde karşılaşılan psikososyal sorunlarla uyumludur. Bununla birlikte çalışmamız bu hastalarda post travma sendromu riski ve sosyal etkileşimde bozulma sorunlarının da yaşanabileceğini ortaya koymuştur.

Vajinal septumda adölesanların tanı aşamasından itibaren tedavi sürecine uyum sağlaması ve psikososyal sorunlar yaşamaması için uygun girişimlerde bulunulmalıdır. Bu noktada sağlık bakım hizmetleri içinde hasta ve ailesiyle en yakın ilişkide bulunan hemşirelere büyük sorumluluk düşmektedir. Bu nedenle, hemşireler, adölesanı ve ailesini yaşanan/yaşanabilecek psikososyal sorunlar açısından değerlendirmelidir. Bu kapsamda hemşireler tarafından sorunun fizyolojik boyutu adölesan ve ailesine açıklanmaIı; hastalığın bundan sonraki süreçlerde yaşam üzerinde oluşturacağı fiziksel sorunlar açıklanarak çözüm önerileri sıralanmalı; hasta tarafından hastalığa atfedilen anlam öğrenilmeli ve hastanın bu konudaki duygularını ifade etmesi sağlanmalıdır (5).

Vajinal septum olan hastaların hemşirelik bakımlarını ele alan çok az çalışmaya rastlandığı için konunun önemini ve güncelliğini koruduğu düşünülmektedir. Bu alanda daha fazla çalışmanın yapılması, psikososyal sorunların hemşirelik bakım sürecinde ele alınması ve psikososyal sorunların etkilerinin ve giderilmesinin uzun vadede gerçekleşmesi göz önünde bulundurularak hastaların taburculuk sonrası evde takip edilmesi önerilmektedir. 


\section{Kaynaklar}

1. Taşkın L. Doğum ve Kadın Sağlığı Hemşireliği. 13. Baskı. Ankara: Akademisyen Tıp Kitabevi, 2016: 736-58.

2. Üstün $Y$, Üstün YE, Zeteroğlu Ş, Şahin G, Kamacı M. A case of transverse vagınal septum diagnosed durıng labor. Erciyes Medical Journal 2005; 27:136-8.

3. Amankwah YA, Haefner HK, Brincat CA. Management of vulvovaginal strictures/shortened vagina. Clinic Obstetric Gynecology 2010;53:125-33. [CrossRef]

4. Behr SC, Courtier JL, Qayyum A. Imaging of müllerian duct anomalies. Radiographics 2012; 32: 233-50. [CrossRef]

5. Yaman Ş, Ayaz S. Hymen tearing in the treatment of vaginal agenesis: Implications on women in Turkey. Journal of Transcultural Nursing 2014; 25: 303-6. [CrossRef]

6. Heller-Boersma JG, Schmidt UH, Edmonds DK. Psychological distress in women with uterovaginal agenesis (Mayer-RokitanskyKüster-Hauser Syndrome, MRKH). Psychosomatics 2009; 50: 277-81. [CrossRef]

7. Weijenborg PT, ter Kuile MM. The effect of a group programme on women with the Mayer-Rokitansky-Küster-Hauser syndrome. BJOG: An International Journal of Obstetrics and Gynaecology 2000;107:365-8.

8. Törüner $K E$, Büyükgönenç L. Çocuk Sağlığı Temel Hemşirelik Yaklaşımları. 2. Baskı. Ankara: Göktuğ Yayıncılık, 2012: 29-36.

9. Çavuşoğlu H. Çocuk Sağlığı Hemşireliği. 9. Baskı. Ankara: Sistem Ofset Basımevi, 2008: 77-8.
10. Erdemir F. Hemşirelik tanıları el kitabı. 13. Baskı. İstanbul: Nobel Tıp Kitap Evleri, 2012: 57-360.

11. Öz F. Sağlık Alanında Temel Kavramlar. 2. Baskı. Ankara: Mattek Matbaacilık, 2010: 130-89.

12. Herman J. Travma ve İyileşme Şiddetin Sonuçları Ev İçi İstismardan Siyasi Teröre (Tosun T, çev.). 2. Baskı, İstanbul: Literatür Yayınları 2011;67-125, 175-255.

13. Kimberley N, Hutson JM, Southwell BR, Grover SR. Well-being and sexual function outcomes in women with vaginal agenesis. Fertility and Sterility 2011; 95: 238-41. [CrossRef]

14. Ismail-Pratt, IS, Bikoo M, Liao LM, Conway GS, Creighton SM. Normalization of the vagina by dilator treatment alone in complete androgen insensitivity syndrome and Mayer-Rokitansky- KusterHauser syndrome. Human Reproduction 2007; 22: 2020-4. [CrossRef]

15. Liao LM, Doyle J, Crouch NS, Creighton SM. Dilation as treatment for vaginal agenesis and hypoplasia: A pilot exploration of benefits and barriers as perceived by patients. Journal of Obstetrics and Gynaecology 2006; 26: 144-8. [CrossRef]

16. Morgan EM, Quint EH. Assessment of sexual functioning, mental health, and life goals in women with vaginal agenesis. Archives of Sexual Behavior 2006; 35: 607-18. [CrossRef]

17. Bean EJ, Mazur T, Robinson AD. Mayer-Rokitansky-Ku“ ster-Hauser Syndrome: Sexuality, Psychological Effects, and Quality of Life. J Pediatr Adolesc Gynecol 2009; 22: 339-46. [CrossRef] 